\title{
Supernovae astrophysics from Middle Age documents
}

\author{
V. F. Polcaro ${ }^{1}$ and A. Martocchia ${ }^{2} \dagger$ \\ ${ }^{1}$ IASF-INAF, Rome, Italy \\ email: polcaro@rm.iasf.cnr.it \\ ${ }^{2}$ OAS, Strasbourg, France \\ email: martok@quasar.u-strasbg.fr
}

\begin{abstract}
The supernova explosion of 1054 AD, which originated the Crab Nebula and Pulsar, is probably the astronomical event which has been most deeply studied by means of historical sources. However, many mysteries and inconsistencies, both among the different sources and between what is deduced by the historical records and the present day astronomical data, are demanding extraordinary efforts by theoretical astrophysicists in order to put all the data in a meaningful framework. An accurate analysis of the historical sources, like the one we are presenting here, may contribute to solve some of these problems.
\end{abstract}

Galactic Supernovae are rare events and their testimonies are extremely important for astrophysics. To date, seven astronomical events documented by historical texts are believed to have been galactic supernovae (see Table 1). Information gathered from the historical sources concerning all of these events have been used in some way in astrophysical studies, though it is not always easy to extract quantitative data from ancient measurements.

Before the Cepheid distance scale was extended by HST to include the host galaxies of many SNe of Type Ia with good photometry, historical Type Ia SNe had been used to compute the Hubble constant by combining their brightness at maximum with the modern distances to their remnant in order to estimate the peak absolute magnitude. For instance, Schaefer (1996), from a careful reconstruction of the Type Ia SN 1572 light curve, obtained a peak magnitude of $\mathrm{V}=-4.53 \pm 0.18$, corresponding to an absolute magnitude of $\mathrm{V}_{o}=-18.64 \pm 0.31$, deriving $\mathrm{H}_{o}=66 \pm 12 \mathrm{~km} \mathrm{~s}^{-1} \mathrm{Mpc}^{-1}$ : this is an astonishing precise result, considering that it was obtained by using data gathered by naked eye more than 400 years ago!

However, it may be risky to use historical astronomical data for astrophysics if they have not been carefully checked from a historical point of view. The most indicative case is the one of SN 185, which was used for calibrating the brightness of Type Ia SNe and hence for deriving the Hubble constant. But, as has been shown by Schaefer (1995), most likely this event was not a supernova, but a transit of comet $\mathrm{P} /$ Swift-Tuttle - indeed the derived value of $\mathrm{H}_{o}$ was the unrealistic one of $\mathrm{H}_{o} \simeq 150 \mathrm{~km} \mathrm{~s}^{-1} \mathrm{Mpc}^{-1}$.

The importance of a careful historical analysis of the historical sources before using them for astrophysical purposes is further illustrated by the case of SN 1054 .

The Song Empire sources were the first to be suggested as witnesses of the birth of the Crab Nebula by Hubble (1928) and Mayall (1939). It was found that they report a date when the Emperor was notified by the astronomer Yang Weide about the 1054 "guest star" appearance (4th July), the length of the period in which this star was visible in daylight (23 days), the date of the last sighting (17th April 1056), and the star position

\section{$\dagger$ Present address: CESR, Toulouse, France.}


Table 1. Possible historical Supernovae

\begin{tabular}{|c|c|c|c|c|c|}
\hline Year & Date & mag & Remnant & SN Type & Source(s) \\
\hline $185 \mathrm{AD}$ & Dec $7(?)$ & $-2(?)$ & RWC $86(?)$ & $\mathrm{Ia}(?)$ Not a $\mathrm{SN}(?)$ & Chinese \\
\hline 393 & Feb $27-28$ & $-3(?)$ & RX J1713.7-3946(?) & & Chinese \\
\hline 1006 & Apr 30 & -7.5 & SNR 1006 & Ia & $\begin{array}{l}\text { Arabic, Chinese, Japanese, } \\
\text { European }\end{array}$ \\
\hline 1054 & Apr 11 & $-4(?)$ & M1 (Crab) & $\mathrm{II}(?) \mathrm{Ib}(?)$ & $\begin{array}{l}\text { Chinese, North American(?), } \\
\text { Arabic, Japanese, European }\end{array}$ \\
\hline 1181 & Aug 6 & $-1(?)$ & $3 \mathrm{C} 58(?)$ & $\mathrm{II}(?) \operatorname{Ib}(?)$ & Chinese, Japanese, European \\
\hline 1572 & Nov 6 & -4 & Tycho SNR & Ia & Tycho Brahe, etc. \\
\hline 1604 & Oct 9 & -3 & Kepler SNR & $\mathrm{Ib}(?)$ & Johannes Kepler, etc. \\
\hline
\end{tabular}

Table 2. The historical records of SN1054 (revised version of Tab.1 from Collins et al., 1999)

\begin{tabular}{|c|c|c|c|c|c|c|}
\hline Date & MJD & Ref. & location & appearance as... & likely $m_{\mathrm{V}}$ & Notes \\
\hline $04 / 11 / 1054$ & 6126 & a. & Fustat & star & & Ibn Butlan \\
\hline $04 / 11 / 1054$ & 6126 & b. & Flanders & bright disk at noon & $\sim-7$ & \\
\hline $04 / 24 / 1054$ & 6139 & c. & Ireland & fiery pillar & & \\
\hline late April 1054 & & d. & Rome & bright light & $<-3.5$ & \\
\hline $05 / 10 / 1054$ & 6155 & e. & Liao Kingdom & star & & Sun eclipse \\
\hline $05 / 14 / 1054$ & 6159 & f. & Armenia & star & & \\
\hline late May 1054(?) & & g. & Italy & very bright star & & \\
\hline late May 1054 & & h. & Japan & new star... as Jupiter & $\sim-4.5$ & \\
\hline June 1054 & & h. & Japan & star & & \\
\hline$\sim 06 / 20 / 1054$ & & & & $\begin{array}{c}\text { Crab in conjunction } \\
\text { with Sun }\end{array}$ & & not visible \\
\hline 07/04/1054? & $6210 ?$ & i. & Song Empire & star... like Venus & $\sim-3.5$ & for 23 days $\left({ }^{*}\right)$ \\
\hline $08 / 27 / 1054 ?$ & $6264 ?$ & i. & Song Empire & star... like Venus & $\sim-3.5$ & for 23 days $\left({ }^{*}\right)$ \\
\hline 1055 & & a. & Constantinople & star & & \\
\hline $04 / 17 / 1056$ & 6863 & i. & Song Empire & no more visible & $>+6$ & \\
\hline $\begin{array}{l}\mathrm{JD}=\mathrm{MJD}+21000 \\
\text { References: a. Di } \\
\text { Leonis e. Sung-sh } \\
\text { hui-yao. } \\
\left(^{*}\right) \text { Datation may }\end{array}$ & of & 1 & $\begin{array}{l}\text { n b. Tractatu } \\
\text { Etum Patmich }\end{array}$ & $\begin{array}{l}\text { us de ecclesia c. Irish } \\
\text { h g. Rampona Chron }\end{array}$ & $\begin{array}{l}\text { nnals d } \\
\text { es h. M }\end{array}$ & $\begin{array}{l}\text { De Obitu Sanc } \\
\text { Getsuki i. Sur }\end{array}$ \\
\hline
\end{tabular}

in the sky. These data made it possible to prove, though with some problems, the link between the historical event and the explosion of the precursor of the Crab Nebula (Mayall \& Oort, 1942; Duyvendak, 1942). Nevertheless, another surely independent Chinese source, the K'i-tan-kuo-chih, the history of the Kingdom of Liao written about $1350 \mathrm{AD}$, refers only briefly to the "guest star", stating that the event occurred near the time of (or "during", following a more recent translation: Collins et al., 1999) a total eclipse of the Sun. Duyvendak (1942) has shown that the only important eclipse of that period occurred on 10th May 1054. This evidence of an earlier date of the SN 1054 explosion has been often neglected because of the contradiction with respect to the date reported by the sources of the more developed Song Empire. On the other hand, the latter texts give us just two photometric points: on 4th July 1054, the star is defined "as luminous as Venus" and thus with $\mathrm{V}=-3.5 \pm 1$; on 17 th April 1056, it is declared "no more visible" and thus having $V \geqslant 5.5$. However, as shown by Collins et al. (1999), 

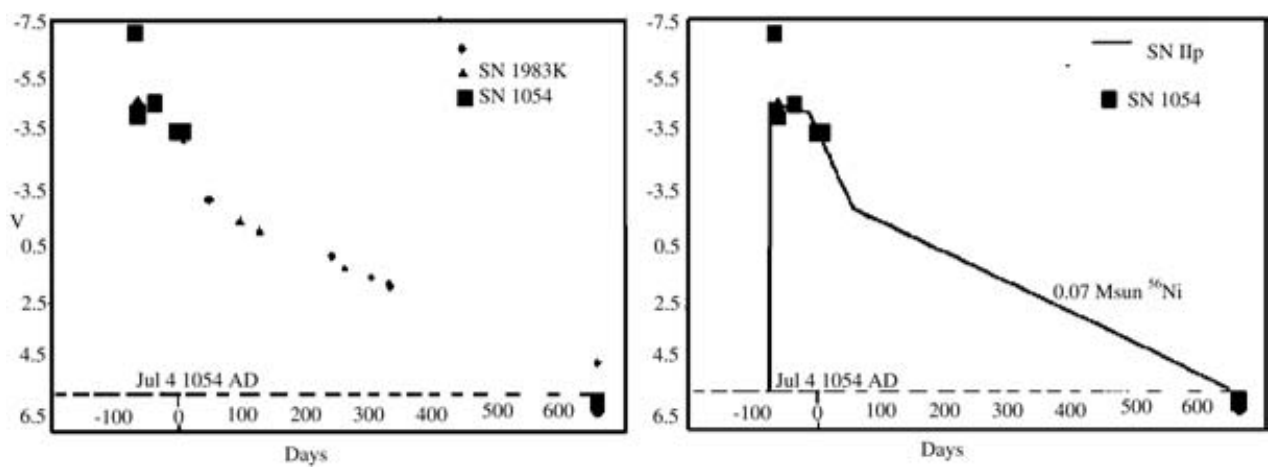

Figure 1. Left: The historical light curve of the SN 1054 overlapped to the photometric points of two modern type II SNe, reduced to the distance of the Crab Nebula. Right: the same light curve compared to a simple model of SN-IIp, assuming a production of $0.07 \mathrm{M}_{\odot}$ of ${ }^{56} \mathrm{Ni}$.

these two photometric points are not compatible with the average light curve of any kind of core-collapse supernova to have exploded on 4th July 1054: they could be only marginally fitted by the average light curve of a Type Ia SN or by a Type II-L SN with its maximum on 20th June. While the first hypothesis is ruled out by the presence of the Crab Pulsar, both hypotheses are actually in contradiction with the Song sources themselves, stating the appearance of the star on 4th July. A problem is that Type II SNe may have significantly different luminosity at peak (although their light curves have a very homogeneous behaviour when the radioactive nuclides decay becomes the dominant energy source: see e.g. Cappellaro \& Turatto, 2001, for a general review of SN types); however, one cannot but assume that there is something wrong in the official Song Court report. And, indeed, we have nowadays the possibility to consider the whole set of data concerning the SN 1054 event. It is witnessed, to our knowledge, by at least 13 primary historical sources all over the world (see Table 2). They are of course much different from each other, both in clarity and in style; however, from the appearance of the reported phenomena, it is often possible to guess the corresponding visual magnitude of the SN 1054. We may therefore try reconstructing a rough light curve, by using the formulas which give the naked eye visibility of astronomical objects (see e.g. Schaefer, 1993). If we overlap to this curve the observed magnitudes of a few modern Type II SNe, scaled to the distance of Crab Nebula (Fig. 1, left), and a simple model of Type IIp $\mathrm{SN}$ with production of $0.07 \mathrm{M}_{\odot}$ of ${ }^{56} \mathrm{Ni}$ (Collins et al., 1999; Sollerman et al., 2001; see Fig. 1, right), we can notice that the fit is fairly good in both cases, though the historical data crowd in the high-luminosity segment of the curve, as obvious, making an actual quantitative "best fit" procedure impossible.

We notice that a single point is out from the fit: that is the one related to the very first appearance of the SN, obtained from the Tractatus de Ecclesia S. Petri Aldenburgensi, the chronicle of the Church of St. Peter in Oudembourg (in present day Belgium) written by an anonymous monk or clerk some 20 years after the reported events. This is the text translation, in full (for the latin original see: Guidoboni, Marmo \& Polcaro, 1994):

And the most blessed Pope Leo, after the beginning of the construction of the aforementioned church of St. Peter, in the following year, on the 18th day before the first of May, a Monday, around midday, happily departed this world. And at the same hour as his leaving of the flesh, not only in Rome, where his body lies, but also all over the world there appeared to men a circle in the sky of extraordinary brightness which lasted for about half an hour. Perhaps the Lord wished to say that he [the Pope] was worthy to receive a crown in Heaven between those who love Him. 
A deep textual analysis of this reference, one of the very few written by an actual eye-witness of the SN 1054, allowed the reconstruction of the exact date of the reported phenomenon as the 11th April 1054, in agreement with the date that can be deduced from the reports of the Arabic scholar Ibn Butlan (Guidoboni et al., 1994). Furthermore, we can observe that in this document, the author describes the phenomenon in neutral terms, unaffected by any set of beliefs: the disk-like shape, the intense brightness and the duration of the phenomenon are all elements common to very different cultures. The author separates the description of the phenomenon from his cautious symbolic interpretation, showing a clear awareness of the different levels of discourse. The Flemish chronicler saw a bright point source at $\sim 30^{\circ}$ from the horizon: in the foggy sky of Flanders in Spring, this would appear exactly like a disk. Such a short optical transient, in the very first 30 minutes following the collapse of a SN-II precursor, could very easily escape the detection even with the nowadays observatories; therefore, if confirmed by further evidences, this testimony could be very important for the understanding of the physics of the core-collapse supernovae.

Thus, if the SN 1054 exploded on 11th April 1054 (as Guidoboni, Marmo \& Polcaro, 1992, first suggested and Collins et al., 1999, demonstrated) it was surely still visible, and very impressive, near to the zenith of the Song capital Kaifeng during the Sun eclipse of 10th May 1054. From this sky configuration and by using the standards of the Chinese astrology, which are perfectly documented, it is easy to reconstruct the omen that must have been deduced at the time: the Sun represents the Emperor (actually, the Emperor was the Sun); the eclipse is a danger for the Emperor's life; moreover, the contemporary presence of the "guest star" indicates the loss of the Heavenly support; therefore the danger is unavoidable: the Emperor will die. It is not surprising that such a terrible omen must have been subject to some form of censorship: what the astronomer Yang Weide did - most probably following the wish of Emperor Renzong himself (Polcaro, 2005) was to censor all the references to the "guest star" preceding its conjunction with the Sun, which occurred at the end of June.

On the other hand, the Chief Astronomer of the Liao kingdom, whose king actually died one year or so after the eclipse, had no reasons to maintain the secret concerning the "guest star" visibility during the eclipse and the related omen.

This is a clear example of the need of taking the historical and cultural context into account, to derive meaningful scientific results from the study of ancient reports.

\section{References}

Cappellaro, E. \& Turatto, M. 2001, in: Proc. of the Meeting The influence of binaries on stellar population studies, Dordrecht: Kluwer Academic Publishers, 2001, Astrophysics and Space Science Library (ASSL), 264, 199

Collins, G.W., Claspy, W.P., \& Martin, J.C. 1999, PASP, 111, 871

Duyvendak, J.J.L. 1942, PASP, 4541, 645.

Guidoboni, E., Marmo, C., \& Polcaro, V. F. 1992, Le Scienze, 292, 24

Guidoboni, E., Marmo, C., \& Polcaro, V.F. 1994, Mem. SAIt, 65, 623

Hubble, E. 1928, PASP Leaflet, 1, 14

Mayall, N.U. 1939, PASP Leaflet 3, 119, 145

Mayall, N.U. \& Oort, J.H. 1942, PASP, 54, 95

Polcaro, V.F. 2005, in: Proc. of SEAC 2005, Isili, Jun 28-Jul 3, 2005

Schaefer, B.E. 1993, Vistas in Astronomy, 36, 311

Schaefer, B.E. 1995, AJ, 110, 1973

Schaefer, B.E. 1996, ApJ, 459, 438

Sollerman, J., Kozma, C., \& Lundqvist, P. 2001, A\&A, 366, 1971 


\section{Discussion}

VAN DEN Heuvel: a) Where was Oudembourg located?

b) I saw in Sky and Telescope once an article about a coin of Byzantium of 1054, where the emperor had a star next to him, while on coins from other years there is no star. Could you comment on this?

PolCARo: Oudembourg is located in the present-day Belgium, not far from Bruges, at a perfect latitude to have the Crab at the right height in the centre of the field of view of a man standing and looking to the flat horizon of Flanders.

Concerning the Byzantium coin, its connection with the SN1054 has been called into discussion, since there is a number of other Byzantine coins, of very different epochs, showing a star near to the Emperors' images. However I think that this particular coin should be actually connected with the Supernova: we have many cases of artistic representations of impressive astronomical events, for instance the transit of the Halley Comet on the "Cappella degli Scrovegni" fresco by Giotto, possibly the SN1181 in the Abbey of San Pietro in Valle Fresco, and many other ones. And, for sure, the SN1054 was a very impressive event.

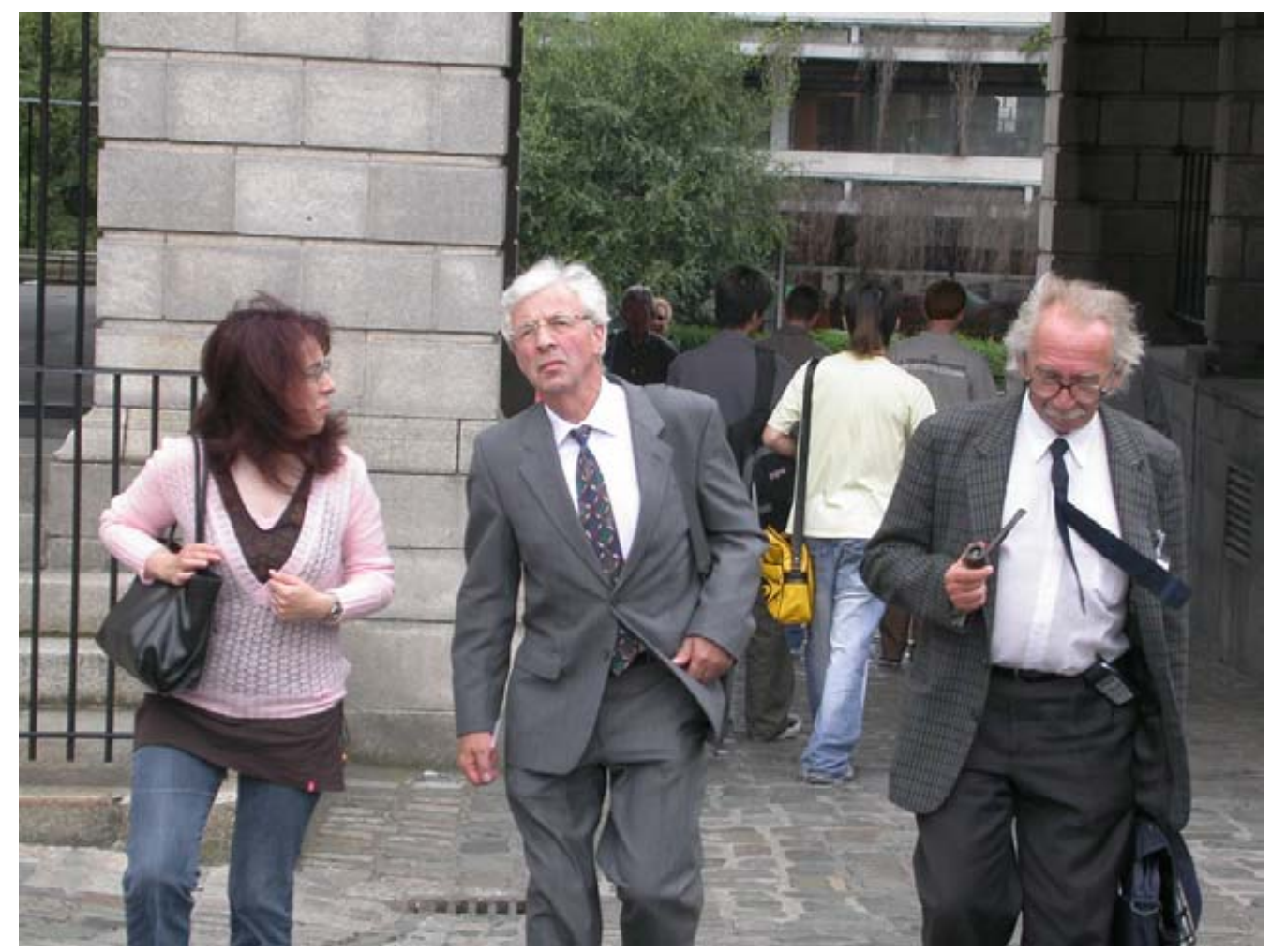

Thoughtful after an Irish lunch. Left to right: Laura Norci, Brian McBreen and Francesco Polcaro, who came first in the Albert Einstein look-alike competition. 